\title{
Fuzzy control of parabolic antenna with friction compensation
}

\begin{abstract}
In this paper a fuzzy logic controller was developed for a parabolic dish antenna system. Friction is one of the disturbances associated such systems and was represented with dead zone in the Simulink block. The effect of the disturbance due to the friction was investigated by simulation using Simulink/MATLAB 2012a software. The results obtained from the system with the fuzzy logic controller were compared with the ones obtained with equivalent proportional derivative controller and it showed that with the fuzzy logic controller the system had better performance and also demonstrates its ability to reduce the effect of friction in parabolic antenna dish systems and most likely other nonlinearities in such systems.
\end{abstract}

Keyword: Fuzzy logic controller; Proportional derivative controller; Friction; Control 